\title{
High strain-rate compression testing of a short-fiber reinforced aluminum composite
}

\author{
M. Guden, I.W. Hall* \\ Mechanical Engineering and Materials Science Program, University of Delaware, Newark, DE 19716, USA \\ Received 22 August 1996; received in revised form 3 December 1996
}

\begin{abstract}
Compression behavior of $15-26 \mathrm{~V}_{\mathrm{f}} \%$ Saffil ${ }^{\mathrm{TM}}$ short-fiber reinforced $\mathrm{Al}-1.17 \mathrm{wt} . \% \mathrm{Cu}$ alloy metal matrix composites has been determined over a strain-rate range of approximately $10^{-4}$ to $2 \times 10^{3} \mathrm{~s}^{-1}$. The strain-rate sensitivity of composite samples at $4 \%$ strain, tested parallel and normal to the plane of reinforcement, was found to be higher than that of unreinforced alloy in the strain-rate range studied. Quantitative analysis of fiber fragment lengths from samples tested to different strain levels showed that, at small strains, high strain-rate testing induced a relatively shorter fiber fragment length distribution in the composite compared to quasi-static testing. At quasi-static strain rates, the fiber strengthening effect was found to increase with increasing $V_{\mathrm{f}}^{\%}$ and was higher in samples tested parallel to the planar random array. The observed anisotropy of the composite at quasi-static strain rates was also observed to continue into the high strain-rate regime. Microscopic observations on composite samples tested quasi-statically and dynamically to a range of strains showed that the major damage process involved during compression testing was fiber breakage followed by the microcracking of the matrix at relatively large strains. Fiber breakage modes were found to be mostly shearing and buckling. (O 1997 Elsevier Science S.A.
\end{abstract}

Keywords: Compression testing; Metal matrix composites; Strain-rate sensitivity

\section{Introduction}

Metal matrix composites (MMCs) are finding steadily more applications in the aerospace, automobile and defense industries. In many of these applications, high strain-rate loading may occur, for example, in the sudden impact of foreign objects on aircraft turbine blades or collisions of cars. Therefore, the high strainrate mechanical response of MMCs is important in present and future applications in these industries.

Knowledge of the quasi-static response of MMCs is needed and constitutes the basic material parameter database for designing with MMCs for structural applications at present. Parameters such as yield strength and modulus are well known and have been studied widely at quasi-static strain rates. The associated fracture mechanisms in MMCs at these rates are also well determined. However, few studies have been conducted on the high strain-rate response of MMCs and most of

* Corresponding author. Tel.: + 1302 8312062; fax: + 1302 8314545; e-mail: hall@me.udel.edu. these have concentrated on particulate and whisker reinforced composites. The main aim of the present study has been to determine the possible rate sensitivity of a short-fiber MMCs properties as compared with the unreinforced alloy.

Harding and Taya [1] carried out tensile testing on $\mathrm{SiC}$ whisker $\left(\mathrm{SiC}_{\mathrm{w}}\right)$ reinforced 2124 aluminum alloy over the strain-rate range from $10^{-3}$ to $1.5 \times 10^{3} \mathrm{~s}^{-1}$ and observed that the yield stress, Young's modulus and fracture strain of the composite increased with the strain rate. Vaziri et al. [2] performed compression tests on $\mathrm{SiC}$ and $\mathrm{Al}_{2} \mathrm{O}_{3}$ particle reinforced 6061 alloys and found a higher strain-rate sensitivity of the flow stress for the composite when compared with the monolithic alloy. Yadav et al. [3] observed the same effect for $\mathrm{Al}_{2} \mathrm{O}_{3}$ particulate reinforced 6061 alloy and suggested that the higher rate sensitivity of the composite is due to the imposed strain rate rather than the changing of the internal structure.

In the examples given above, no significant fracture of the reinforcement is expected during quasi-static or dynamic loading due to its low aspect ratio. However, 
in the case of short-fiber reinforced composites tested quasi-statically and dynamically, fiber fracture may be expected to affect the mechanical response of the composite because fiber fracture can cause a decreasing load carrying ability and, hence, lcad to catastrophic stress relaxation in the matrix. The critical aspect ratio of the reinforcement depends on the matrix yield stress and, therefore, any increase of yield stress will induce a lower critical fiber aspect ratio and subsequently cause fracture of fibers to smaller fragment lengths. Therefore, in contrast to particulate and whisker reinforced MMCs, fiber fracture effects may be important factors affecting the dynamic mechanical properties of shortfiber reinforced MMCs.

In the present study we have observed the static and dynamic mechanical property response of a short-fiber reinforced $\mathrm{MMC}$, and considered fiber fracture effects and other basic mechanical properties. MMCs and the corresponding unreinforced alloy are compared in order to isolate the effect of fibers on the mechanical properties. The quasi-static mechanical properties of Saffil reinforced aluminum and magnesium alloys are well known [4-6]. However, the majority of these studies have considered only tensile properties and there exists little information on the compression properties [7], even at quasi-static rates of strain. It is, therefore, believed that this study also provides considerable new information on the compression properties of shortfiber MMCs over a wide strain-rate range. Fiber orientation effects are included by testing the MMC in different directions.

\section{Experimental}

\subsection{Material characterization}

The composite material studied contained approximately 15,20 or 26 vol. \% ( $V_{\mathrm{f}}^{\%}$ ) of Saffil (ICI Trade Mark) short fibers, about $3 \mu \mathrm{m}$ in diameter and about $500 \mu \mathrm{m}$ in length before processing, in an $\mathrm{Al}-$ $1.17 \mathrm{wt} . \% \mathrm{Cu}$ alloy matrix. Samples were produced in the form of discs $20 \mathrm{~mm}$ thick and $100 \mathrm{~mm}$ in diameter by a squeeze casting (pre-form infiltration) process by Honda $\mathrm{R}$ and $\mathrm{D} \mathrm{Co}_{0}$, Japan. $\mathrm{A} \mathrm{SiO}_{2}$ binder was used to give integrity to the pre-form. During squeeze casting, pressure is applied to the solidifying liquid metal so that it infiltrates the interstices of a pre-form. The direction of the pressure is normal to the plane of the pre-form and leads to an almost planar-random preferred fiber orientation with resulting microstructural and mechanical property anisotropy. Fig. 1 shows the approximately planar random fiber distribution. All samples were given a homogenizing heat treatment to minimize microstructural differences between unreinforced and composite samples.
In order to identify fiber orientation effects, slices were cut from orientations such that the testing direction would be normal to $(\mathrm{N})$, or parallel to $(\mathrm{P})$, the planar random plane of the as-received composite. In the $\mathrm{P}$ orientation, therefore, fibers are inclined to the loading axis over the whole range of angles between 0 and $90^{\circ}$ whereas, in the $\mathrm{N}$ orientation, fibers are almost normal to the loading direction except for minor inclinations out of the planar random plane. Cylindrical compression samples $8 \mathrm{~mm}$ in diameter, and with an aspect ratio (length/diameter) of 1, were prepared by core drilling. The specimen faces were polished to a 3 $\mu \mathrm{m}$ diamond finish to ensure flat and closely parallel surfaces for split Hopkinson pressure bar testing.

For the determination of fiber fragment lengths, small samples of tested and untested composite were digested with $30 \%$ IICl to remove the matrix. After complete digestion of the sample, the acid was gently agitated and a drop of solution was dried either on a glass microscope slide or $1 \mathrm{~m}$ filter paper. The former were used for quantitative fiber length measurements using optical microscopy and computerized image analysis. The latter wete gold coated for scanning electron microscopy (SEM) and used for qualitative observation of the fiber fragment size distribution.

\subsection{Mechanical testing}

Quasi-static and dynamic compression tests were conducted using a screw-driven Instron machine and a split Hopkinson pressure bar (SHPB) respectively. Both types of tests were conducted on specimens with the same aspect ratio. Tests were conducted on composite and identically produced but unreinforced matrix material in order to separate the effects of matrix and reinforcement on the compression behavior.

In quasi-static tests. strain gages were mounted on the side of each specimen and strain values up to about

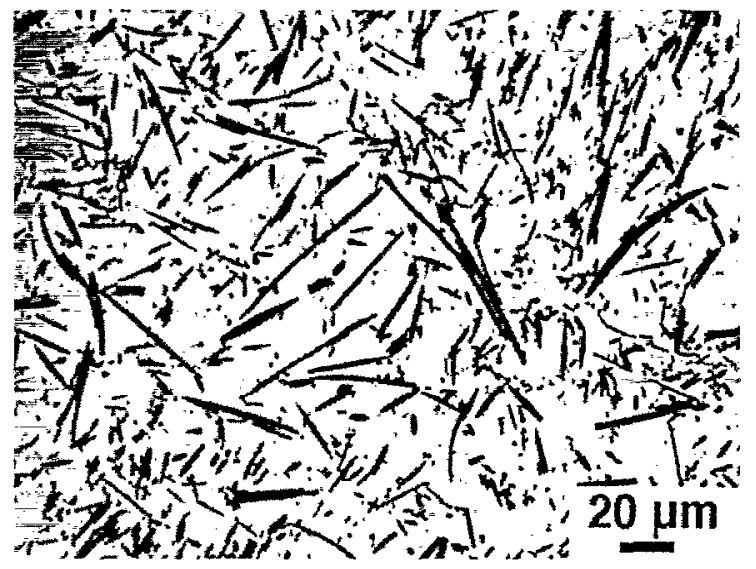

Fig. 1. Untested composite showing the microstructure in $\mathrm{N}$ orientation. 


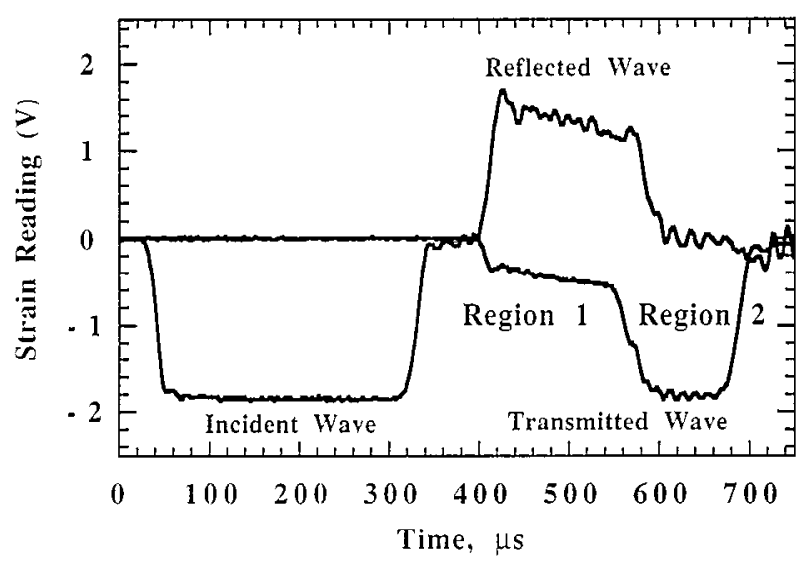

Fig. 2. Typical SHPB wave forms obtained using a steel collar to restrict strain in the specimen.

$5 \%$ were obtained directly from the gages: higher strains were calculated from the machine output. Some of the Instron tests were conducted until the strain gage detached, and the final strain of the sample was measured with a micrometer and compared with the strain gage readings. Negligible difference was found between measured strain and strain gage readings, showing nearly uniform uniaxial compression of the samples.

The SHPB apparatus consists of $19 \mathrm{~mm}$ diameter Inconel 718 striker, incident and transmitter bars which are 724, 3658 and $1830 \mathrm{~mm}$ in length, respectively. Further details of the specific SHPB apparatus can be found elsewhere [8]. In order to recover samples tested at different strain rates but to similar strain levels, for comparison of microstructure and the extent of fiber fragmentation, some tests were carried out with large diameter ring-shaped steel collars of different lengths to restrict the axial strain in the specimen. The collars were loose-fitting and imposed no radial constraint. Typical test data obtained using a collar are shown in Fig. 2 in which the transmitted wave can be seen to be divided into two regions. The first region shows elastic and plastic deformation of the specimen and the second region corresponds to plastic deformation of the specimen and elastic deformation of the collar. Since deformation in the second region is dominated by elastic deformation of the collar, plastic deformation of the specimen is limited to a small inertial value depending on the strain rate and the strain involved in each test. For example, for a specimen which experienced a total strain of $7.0 \%$ at the highest strain rate used in the tests, only $0.3 \%$ occurred in the second region. Therefore, specimen deformation in the second region can be neglected. More detailed information about the SHPB technique and data reduction method are given elsewhere [9].

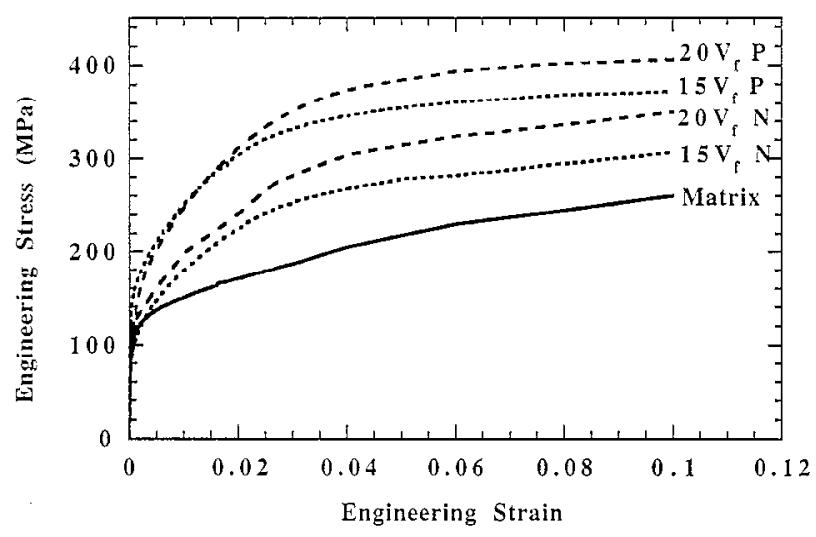

Fig. 3. Typical quasi-static stress-strain curves of composite and matrix to about $5 \%$ strain using strain gaged samples.

\section{Results}

\subsection{Quasi-static testing}

Typical quasi-static $\left(\sim 1 \times 10^{-4} \mathrm{~s}^{-1}\right)$ stress-strain curves of the MMCs and matrix samples are shown in Fig. 3; the strain gages detached after approximately $5 \%$ strain but samples never broke. (The sample designation shows fiber volume fraction, and testing direction, either normal $(\mathrm{N})$ or parallel $(\mathrm{P})$ to the planar random fiber plane.) The 15 and $20 \mathrm{~V}_{\mathrm{f}}^{\%}$ composites were tested in both $\mathrm{P}$ and $\mathrm{N}$ directions, while $26 V_{\mathrm{f}}^{\%}$ composites was only tested in the $\mathrm{N}$ direction.

The strengthening effect of the fibers is shown in Fig. 4 which presents the flow stresses of the composite samples at $4 \%$ strain minus the corresponding flow stress of the unreinforced matrix, $\left(\sigma_{c}^{*}-\sigma_{m}^{*}\right)$. The flow stress at $4 \%$ strain was chosen for reasons which will be explained further below. Strengthening of the samples tested in the $\mathrm{P}$ direction is found to be significantly higher than those of samples tested in the $\mathrm{N}$ direction. For example, the ratio of flow stresses at $4 \%$ strain in the $\mathrm{P}$ and $\mathrm{N}$ directions for 15 and $20 V_{\mathrm{f}}^{0} \%$ samples are found to be about 1.3 and 1.25 , respectively. These

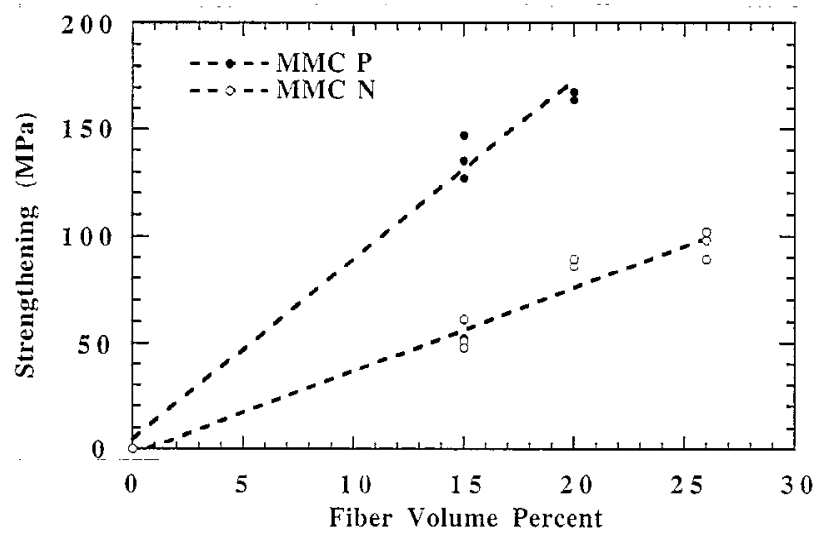

Fig. 4. Fiber strengthening at $4 \%$ strain vs. $V_{\mathrm{f}} \%$ at quasi-static strain rates. 


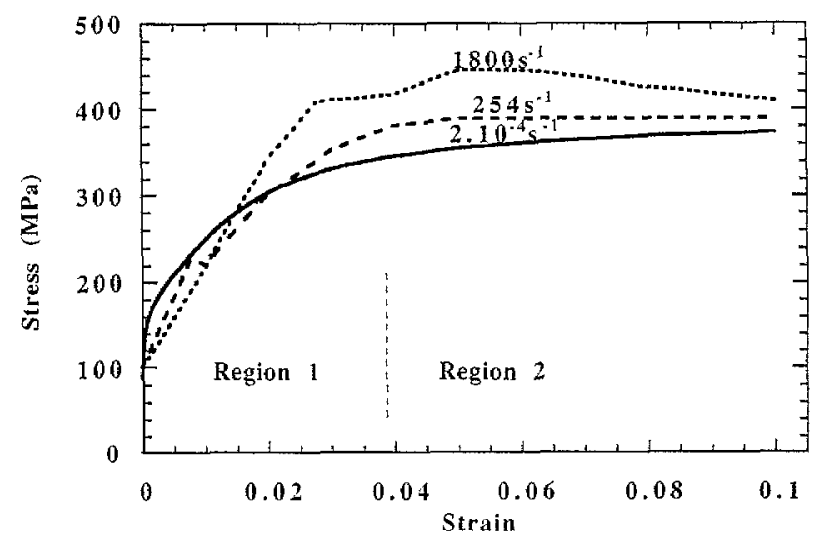

Fig. 5. Typical stress-strain curves for the $15 V_{\mathrm{f}}^{\mathrm{o}} \% \mathrm{P}$ composite samples at quasi-static, intermediate and high strain rates.

compare with 1.3 [7] and 1.2 [10] obtained elsewhere for the compressive fracture strength of Saffil reinforced $\mathrm{Mg}$ MMCs. The highest fiber strengthening effect measured, $82 \%$, was for the $20 V_{\%} \%$ P samples. The strengthening effect for $\mathrm{N}$ samples was relatively lower, reaching only $48 \%$ for $26 V_{\mathrm{f}}^{\%} \%$ samples.

Although the tensile fracture strain of the Saffil fibers is reported to be about $0.7 \%$ [11], the work hardening rate was not observed to decrease substantially before about $3 \%$ strain. Therefore, continued strengthening of the matrix by short fibers after strains equivalent to their fracture strain is due to their being subsequently reloaded and reduced to shorter and shorter lengths, as will be demonstrated below. Similar continued strengthening effects are observed in compression testing of Saffil and chopped $\mathrm{Al}_{2} \mathrm{O}_{3}$ fiber reinforced aluminum MMCs $[12,13]$.

\subsection{High strain-rate testing}

The 15,20 and $26 V_{\%}^{\%} \%$ composite samples were compression tested in the $\mathrm{P}$ and $\mathrm{N}$ directions over the strain-rate range of approximately $1 \times 10^{-4}$ to $2 \times 10^{3}$ $\mathrm{s}^{-1}$. The trends in the data were essentially similar for all the $V_{\mathrm{f}}$ values although, of course, the $20 V_{\mathrm{f}}^{0} \%$ data lay higher than the $15 V_{\mathrm{f}}^{\%} \%$ and so forth. Consequently, only data for the $15 \%$ composites are discussed in detail below and typical stress-strain curves of the composite samples are presented in Fig. 5, at quasi-static, intermediate and high strain rates. Corresponding flow stress values are seen to increase with increasing strain rate.

The conventional means of presenting the effect of strain rate on the flow stress is to plot flow stress values, at a specific strain, as a function of the logarithm of the strain rate. This kind of representation eliminates experimentally unavoidable fluctuations of the stress value at very high strain rates; however, choice of the specific strain depends on several parameters. For example, it is known that the early, low strain, data obtained from SHPB tests yield unreliable material properties because several microseconds are necessary to achieve conditions of homogeneous deformation. The lower strain rates used in the present SHPB tests, however, produced a final strain of only about $4 \%$ and, consequently, $4 \%$ was chosen as the comparison strain value for analysis. Results show that $4 \%$ strain in this study marks a transition region in work hardening behavior, allowing the inclusion of fiber fracture effects in the subsequent analysis.

The $15 \%$ P composite sample stress-strain curves of Fig. 5 may, then, be considered in two distinct regions corresponding broadly to (i) an initial region of high work hardening rate until about $4 \%$ strain and (ii) a region of relatively reduced work hardening rate. In region 1 , increasing strain rate greatly increased the work hardening rate of the composite. In region 2 , increasing strain rate reduced the work hardening compared to the initial region. A similar effect of strain rate on the stress-strain curves was also observed for $15 V_{\mathrm{f}}^{\%} \%$ $\mathrm{N}$ samples but the magnitude of these effects was greatly reduced.

The variations of the flow stresses at $4 \%$ strain are shown as a function of (the logarithm of the) strain rate in Fig. 6 for the $15 \% \% \mathrm{P}$ and $\mathrm{N} \mathrm{MMCs}$ and matrix alloy. There is no universally adopted method of defining the strain-rate sensitivity for such tests but, using an approach similar to that of Follansbee [14], linear interpolation of the high strain rate $\left(>\sim 1000 \mathrm{~s}^{-1}\right)$ data yields a reasonable fit to the following equation:

$\sigma(\dot{\varepsilon})=\sigma_{0}+n \dot{\varepsilon}$

where $\sigma(\dot{\varepsilon})$ is the flow stress at any strain rate, $\sigma_{0}$ is the stress at a reference strain rate which is taken here to be the quasi-static value, $n$ is the slope, i.e., a measure of the strain-rate sensitivity, and $\dot{\varepsilon}$ is the strain rate. The calculated constants of Eq. (1) for the composite samples and the matrix alloy are given in Table 1 together with corresponding regression constants. The strain-

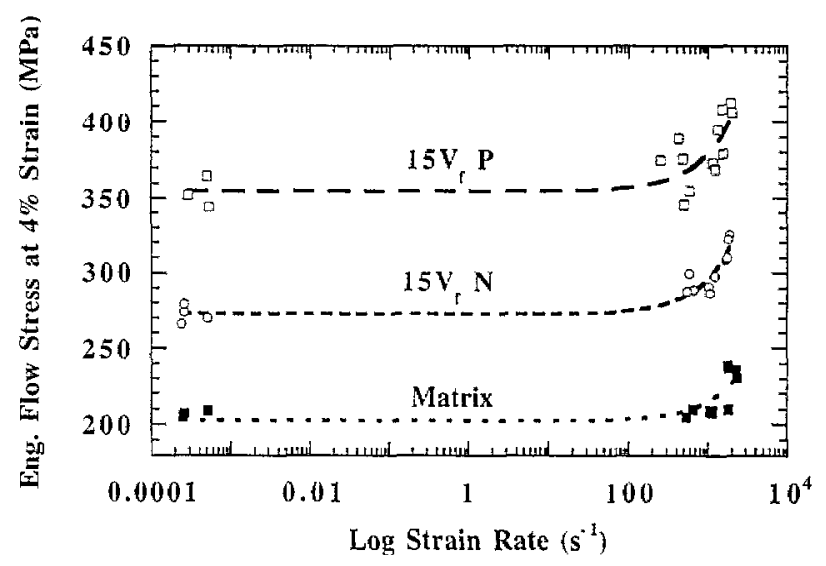

Fig. 6. Flow stress at $4 \%$ strain vs. log strain rate for composite and matrix samples with linear interpolation. 
Table 1

The constants of Eq. (1) for composite and matrix samples

\begin{tabular}{lllll}
\hline Material & $\sigma_{0}(\mathrm{MPa})$ & $n(\mathrm{MPa} \cdot \mathrm{s})$ & Regression constant & Strain-rate range $\left(\mathrm{s}^{-1}\right)$ \\
\hline $15 V_{\mathrm{f}} \% \mathrm{P}$ & 355 & 0.025 & 0.77 & $1 \times 10^{-4}-2 \times 10^{3}$ \\
$15 V_{\mathrm{f}}^{0} \% \mathrm{~N}$ & 273 & 0.024 & 0.93 & $1 \times 10^{-4}-2 \times 10^{3}$ \\
$20 V_{\mathrm{f}}^{3} \% \mathrm{P}$ & 375 & 0.020 & 0.81 & $1 \times 10^{-4}-2 \times 10^{3}$ \\
$20 V_{\mathrm{f}}^{0} \% \mathrm{~N}$ & 307 & 0.024 & 0.97 & $1 \times 10^{-4}-2 \times 10^{3}$ \\
$26 V_{\mathrm{f}}^{\circ} \% \mathrm{P}$ & 423 & 0.035 & 0.75 & $4 \times 10^{2}-2.3 \times 10^{3}$ \\
$26 V_{\mathrm{f}}^{0} \% \mathrm{~N}$ & 306 & 0.025 & 0.89 & $1 \times 10^{-4}-1.2 \times 10^{3}$ \\
Matrix & 203 & 0.012 & 0.77 & $1 \times 10^{-4}-2.4 \times 10^{3}$ \\
\hline
\end{tabular}

rate sensitivity of the composite, as described by the constant $n$, is approximately double that of the unreinforced matrix alloy.

Alternatively, the strain rate sensitivity may be defined in the present context as:

Strain-rate sensitivity $=\frac{\sigma_{\mathrm{DY}}-\sigma_{\mathrm{QS}}}{\sigma_{\mathrm{QS}}}$

where $\sigma_{\mathrm{DY}}$ and $\sigma_{\mathrm{QS}}$ are the dynamic and quasi-static flow stresses at constant strain. Taking $\sigma(\dot{\varepsilon})$ as the dynamic flow stress and $\sigma_{0}$ as the quasi-static flow stress and using the data given in Table 1 , the strainrate sensitivity of the composite is again found to be higher than that of the matrix. The highest strain-rate sensitivity is observed in the $15 V \% \mathrm{~N}$ composite, approximately 0.18 at about $2000 \mathrm{~s}^{-1}$ and $4 \%$ strain, followed by values of about 0.14 and about 0.12 for $15 V_{\mathrm{f}} \% \mathrm{P}$ composite and unreinforced matrix samples, respectively.

These results clearly show that, however it is measured, the rate sensitivity of the composite is higher than that of the unreinforced alloy. The observed anisotropic mechanical response of the $\mathrm{MMC}$ within the $\mathrm{P}$ and $\mathrm{N}$ directions has been observed in other studies $[7,12,15]$ but the present results show the effect to be more pronounced in compression than in tension.

\subsection{Microscopy}

The critical fiber length $\left(l_{c}\right)$, is usually expressed in terms of fiber fracture strength $\left(\sigma_{f}\right)$, fiber diameter $(d)$, and the interfacial shear stress, $\tau_{i}$, which is itself frequently approximated as being half the matrix yield stress $\left(\sigma_{\mathrm{YM}}\right)$. Thus:

$l_{\mathrm{c}}=\frac{d \sigma_{\mathrm{f}}}{2 \tau_{\mathrm{i}}}$

In Eq. (3), $d$ is taken as the average fiber diameter, $\tau_{\mathrm{i}}$ is taken as $65 \mathrm{MPa}$ from quasi-static compression testing and $\sigma_{\mathrm{f}}$ has been given as $2000 \mathrm{MPa}$ [11]. With these values, $l_{\mathrm{c}}$ is calculated to be $46 \mu \mathrm{m}$, although this is only an approximation since the exact value of the interfacial shear strength and the compression strength of the Saffil fiber are not known. The predicted $l_{\mathrm{c}}$ value is much smaller than the initial fiber length in the MMC and it is, therefore, expected that multiple fiber fracture will occur depending on the relative values of matrix and interface strengths.

Tested composite samples were sectioned and polished along the loading direction for identification of damage formation mechanisms and leached samples were used for observation of the extent of fiber fragmentation. Both quasi-statically and dynamically deformed samples showed extensive fiber fragmentation which was cumulative as the strain increased. In addition, increasing strain levels induced other types of damage.

Fibers parallel, or at a small angle, to the loading axis fractured mostly by buckling and/or shearing. Buckling was more common in the regions where the fibers were relatively closely spaced (Fig. 7(a)). Shearing was more common in matrix rich regions and/or where fibers were inclined at a large angle to the loading direction (Fig. 7(b)). Fibers normal to the loading direction were also fractured. Closely spaced or adjacent fibers frequently fractured in the same plane because of the absence of matrix to provide effective crack blunting (Fig. 7(c)).

Although microcracking was not observed in the matrix at small strains, microcracks were found between the fragments of the fractured fibers or the very closely spaced fibers at large strains. The crack path was observed to follow the fractured side of the fibers showing their efrect as stress raisers in the matrix. No void formation, which is widely observed in uniaxial tensile testing of short-fiber composites, was observed in the matrix because it is suppressed by the compressive hydrostatic pressurc. This is clearly the reason for the high capacity for plastic deformation of the composite samples in compression.

Typical distributions of fibers extracted from untested and tested samples at relatively high strain rates are shown in Fig. 8(a)-(d). Fig. 8(a) shows fibers extracted from the untested composite sample and, although they are generally long, occasional small fragments are seen which arise during the manufacturing process. Fig. 8(b) and (c) show fibers extracted from the $15 V_{\mathrm{f}} \% \mathrm{P}$ and $\mathrm{N}$ samples tested at about $1 \times 10^{3} \mathrm{~s}^{-1}$ to 
approximately $50 \%$ strain. In both samples, fibers are seen to be very heavily fragmented, demonstrating both the effectiveness of load transfer and the homogeneity of deformation in these compression tests. Detailed

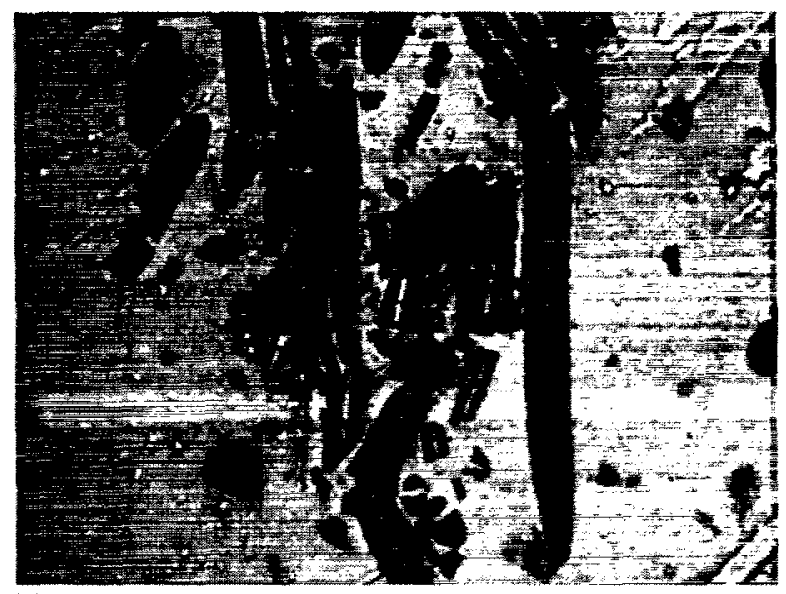

(a)

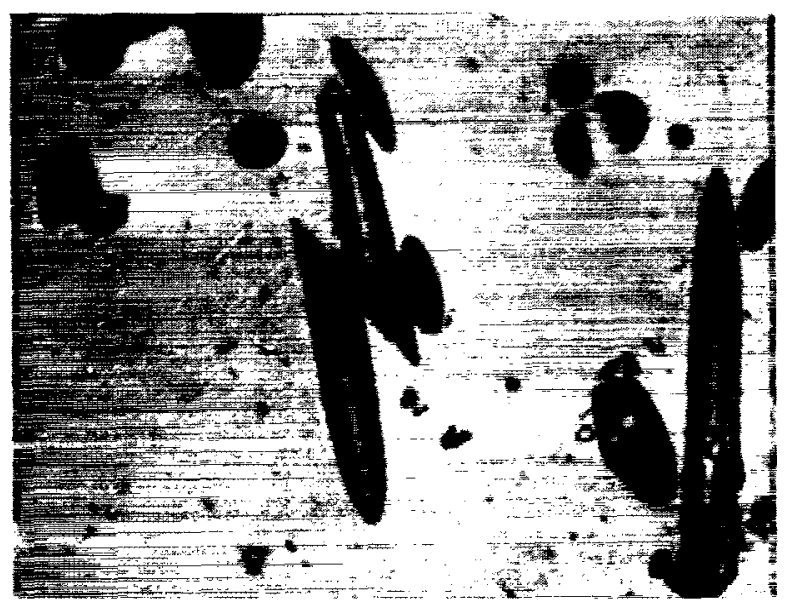

(b)

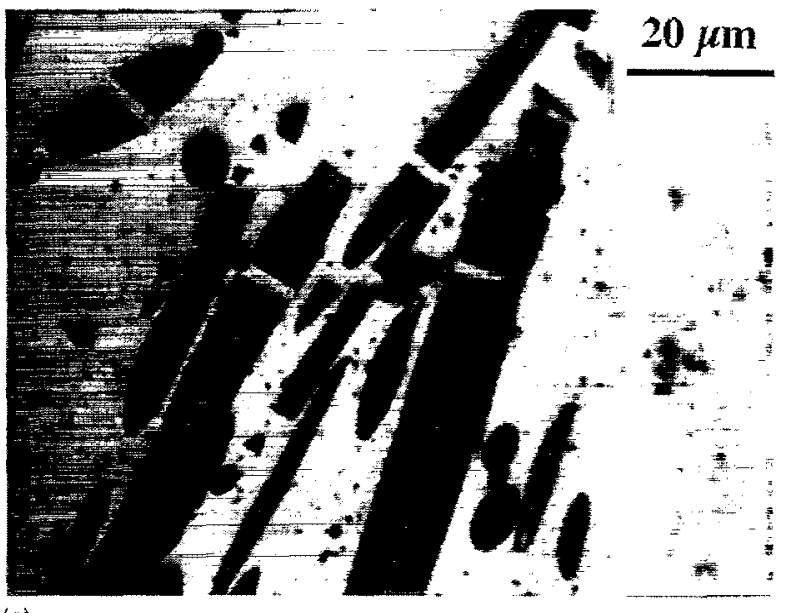

(c)

Fig. 7. Optical mictographs of $15 \% \%$ P samples: (a) fiber failure by buckling in sample tested at $1.5 \times 10^{3} \mathrm{~s}^{-1}$ to $7 \%$ strain; (b) fiber failure by shearing in sample tested at $2 \times 10^{-4} \mathrm{~s}^{-1}$ to $8 \%$ strain; and (c) cumulative fiber fracture in sample tested at $2 \times 10^{-4} \mathrm{~s}^{-1}$ to $8.5 \%$ strain. examination of the figures shows that some fibers were collectively fractured to the smaller sizes while still retaining their original connections to each other even though the total strains involved were large.

Fig. 8(d) shows fibers cxtracted from a $15 \% \mathrm{~F}$ sample tested to about $7 \%$ strain at about $1.5 \times 10^{3}$ $\mathrm{s}^{-1}$. The average fiber length is still quite large, showing that, although underway, fiber fragmentation is far from complete at this strain. Similar trends in fiber fragmentation were also observed in samples tested at quasi-static strain rates.

Statistical fiber fragment length distributions for the tested composite samples were obtained by counting at least 2000 fibers in several fields for each sample and the results are shown in Fig. 9. These samples were tested in the $\mathrm{P}$ direction at quasi-static and dynamic strain rates to the strains indicated on the figure, which also includes the untested sample probability/fiber length data. Since fiber length counting for the untested specimen could only be performed on fibers which actually separated from the preform during acid digestion, Fig. 9 probably underestimates the actual fiber length distribution in the untested specimen because many of the longer fiber's did not detach. Nevertheless, the untested sample's fiber length distribution can be used to give qualitative information in order to estimate the extent of fiber fracture at relatively small strains.

As seen from Fig. 9, both quasi-static and high strain-rate testing induced increased severity of fiber fracture during compression testing as the strain increased. Fig. 10 shows the median of the fiber fragment length for the samples tested both at quasi-static and dynamic strain rates as a function of strain. The initial region corresponds to region 1 of Fig. 5, where the strain hardening rate in the composite is relatively high. In this initial region, the median fiber length was rapidly reduced until about $5 \%$ strain. Thereafter, in region 2, fiber fracture events proceeded at a reduced rate compared to region 1 up to large strains, e.g., about $33 \%$. The effect of strain rate on fiber fracture can also be seen in Fig. 10 since the medians of the fiber lengths of samples tested at high strain rates are smaller than those of the samples tested at quasi-static strain rates.

\section{Discussion}

Previous studies have shown that metallic materials such as copper [14] and aluminum [16] show increased strain-rate sensitivity at strain rates in excess of approximately $10^{3} \mathrm{~s}^{-1}$. This increase in strain-rate sensitivity is interpreted as a change in the deformation mechanism. Below about $10^{3} \mathrm{~s}^{-1}$. deformation is believed to be controlled by thermal activation and the strength of the material increases slowly, if at all, with the strain rate. 


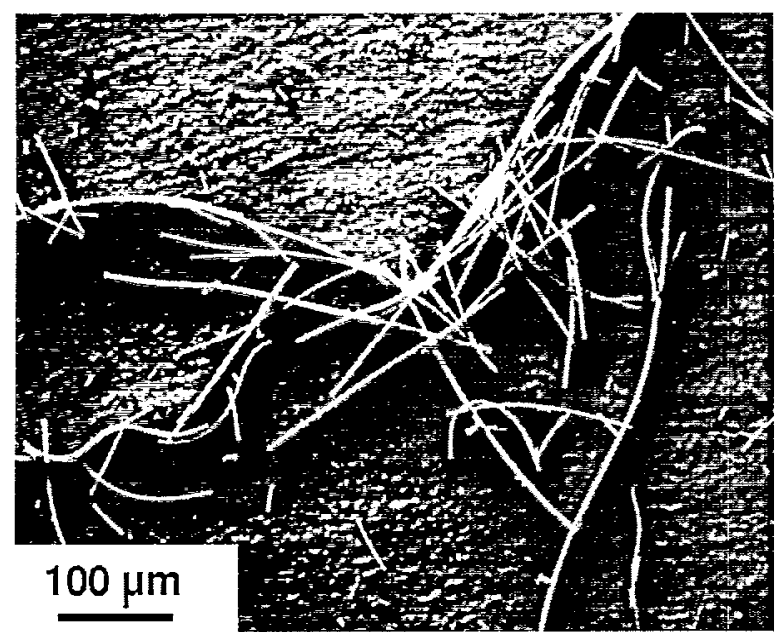

(a)

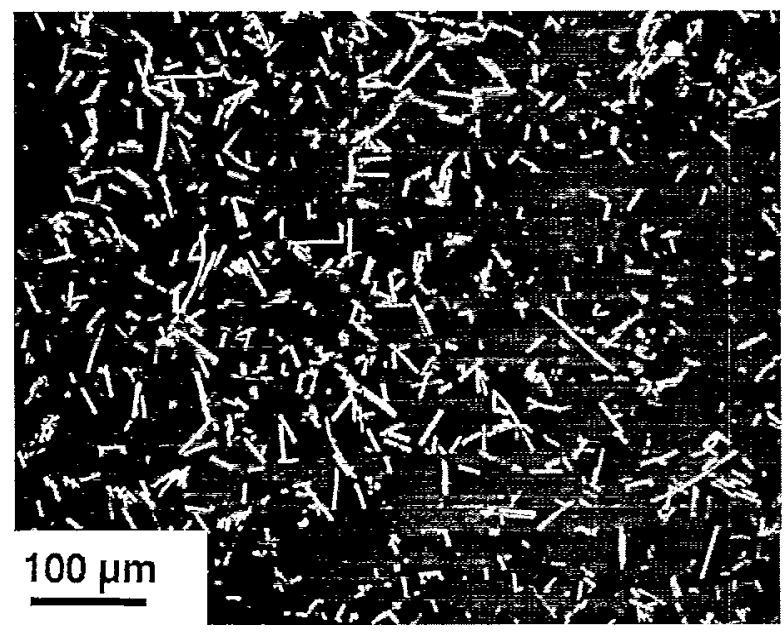

(c)

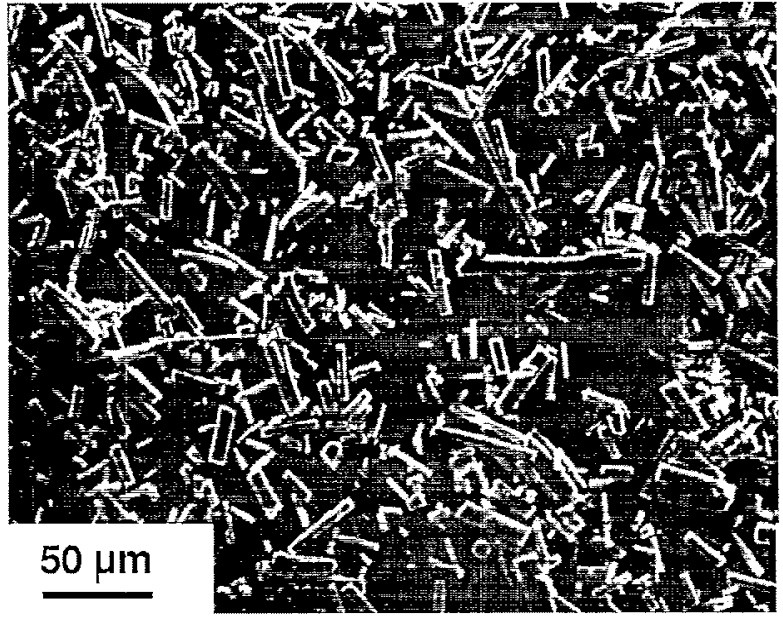

(b)

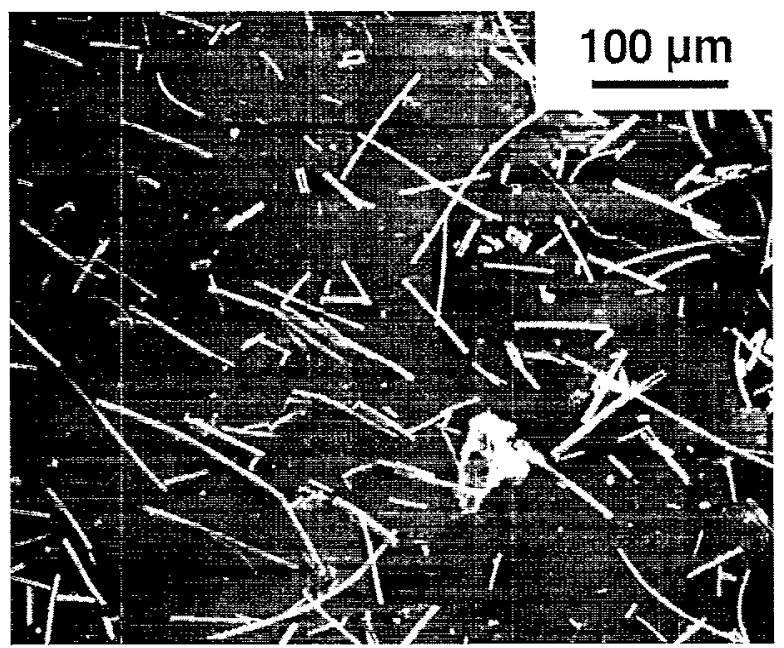

(d)

Fig. 8. SEM micrographs showing typical fiber size distribution: (a) untested composite sample $15 V_{\mathrm{t}}^{\%} / \mathrm{s}$ (b) $15 V_{\mathrm{t}} / 0 \mathrm{P}$ sample tested at $1 \times 10^{3} \mathrm{~s}-1$ to about $50 \%$ strain; (c) $15 \% \% \mathrm{~N}$ sample tested at $1 \times 10^{3} \mathrm{~s}^{-1}$ to about $50 \%$ strain; (d) $15 \mathrm{~V}_{\mathrm{f}} \% \mathrm{P}$ sample tested at about $1.5 \times 10^{3} \mathrm{~s}-1$ to approximately $7 \%$ strain.

The change of deformation mechanism after about $10^{3}$ $\mathrm{s}^{-1}$ is interpreted as a result of the increasing importance of a dislocation drag mechanism and the strength/strain-rate dependence becomes linear in this region [17]. This explanation of the strain-rate-dependent strength of common metallic materials applies also to the unreinforced matrix material tested in this study since no appreciable rate sensitivity is observed at strain rates below about $10^{3} \mathrm{~s}^{-1}$. However, the increased rate sensitivity of the composite samples over the matrix alloy cannot be explained with the above description.

The continuum mechanics-based approach to the tensile strength of composites containing one-, two- and three-dimensional random fiber distributions takes the matrix contribution to the composite strength as the product of the matrix volume fraction $\left(V_{\mathrm{m}}\right)$ and the matrix stress $\left(\sigma_{\mathrm{m}}\right)$. The contribution of the fibers is, however, a complex function of fiber volume fraction $\left(V_{i}\right)$, fracture strength of the fiber $\left(\sigma_{\mathrm{f}}\right)$, fiber length $(l)$ and diameter $(d)$, interfacial shear strength $\left(\tau_{i}\right)$, and an efficiency factor $(C)$ which takes values of $1,0.5$ and 0.25 for one-, two- and three-dimensional fiber distribution cases, respectively [18]. The situation in compression is more complex because of failure modes related to fiber buckling but considering the above parameters, and based upon the rule of mixtures, the strength of the composite $\left(\sigma_{c}\right)$ may still be expressed as follows:

$\sigma_{\mathrm{c}}=V_{\mathrm{m}} \sigma_{\mathrm{m}}+C V_{\mathrm{f}} \sigma_{\mathrm{f}} f n\left(d, l, \tau_{\mathrm{i}}, \sigma_{\mathrm{f}}\right)$

Assuming initially that $\sigma_{\mathrm{f}}$ is strain-rate independent, the only contribution to the composite high strain-rate strength dependence is the matrix itself. The matrix contribution can be calculated as follows: (a) a contribution from the first term due to the increase of the flow stress of the matrix at high strain-rates; (b) a contribution from the second term due to the increase of the interfacial shear stress, $\tau_{i}$, which arises from the increased matrix yield strength, with strain rate. The 


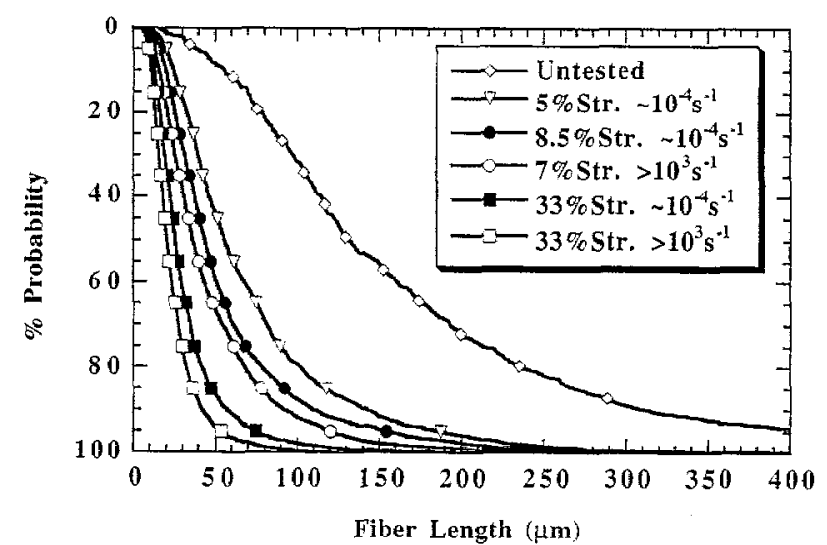

Fig. 9. Probability vs. fiber length for $15 V_{\mathrm{f}} \% \mathrm{P}$ composite samples tested quasi-statically and dynamically to different strains.

contribution from (a) can be easily calculated using $V_{\mathrm{m}}$ and the constants given in Table 1 and is found to be nearly $20 \mathrm{MPa}$ at a strain rate of $2 \times 10^{3} \mathrm{~s}^{-1}$ and $4 \%$ strain. The increase in matrix stress is not, therefore, sufficient to explain the increase of the composite stress at high strain rates $\left(\sim 50\right.$ and $48 \mathrm{MPa}$ for $15 V_{\mathrm{f}}^{0} \% \mathrm{P}$ and $\mathrm{N}$ samples, respectively, at $2 \times 10^{3} \mathrm{~s}^{-1}$ and $4 \%$ strain). The contribution from (b) is hard to calculate at this point since the compressive fracture strength of Saffil fibers is not known. It is clear that an increase in yield stress of the matrix increases the $f n\left(d, l, \tau_{\mathfrak{i}}, \sigma_{\mathrm{f}}\right)$ term in Eq. (4) but, again, this increase is expected to be too small to account for the increase of stress in the composite samples at high strain rates. Using the equation for tensile deformation [5] as an approximation:

$\sigma_{\mathrm{c}}=V_{\mathrm{m}} \sigma_{\mathrm{m}}+C V_{\mathrm{f}} \sigma_{\mathrm{f}}\left(1-\frac{\sigma_{\mathrm{f}} d}{2 l \sigma_{\mathrm{YM}}}\right)$

yields a value of the order of $<4 \mathrm{MPa}$.

Increased strain-rate sensitivity of particulate and whisker reinforced MMCs has also been reported by other authors and several different explanations have been advanced for the increased rate sensitivity of the

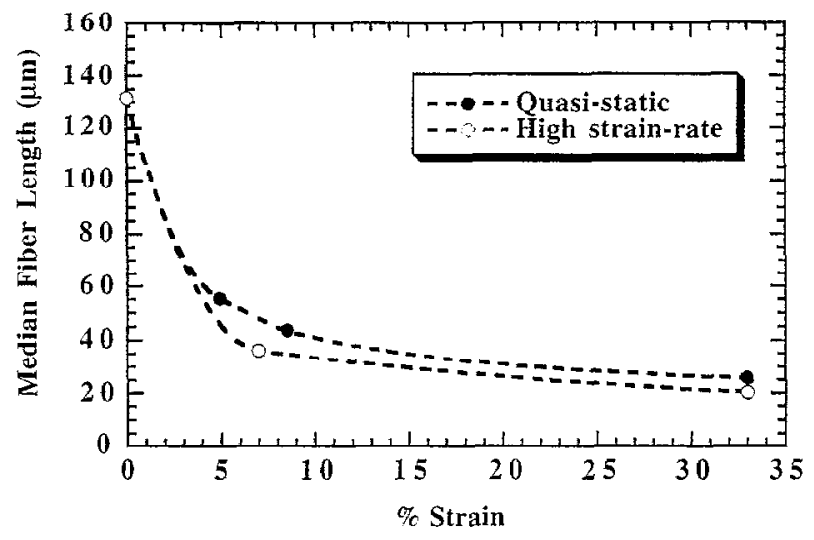

Fig. 10. Median of fiber length vs. \% strain for samples shown in Fig. 9.
MMCs over the matrix alloy. For example, Yaday et al. [3] gave two possible reasons: (i) change of the mobile dislocation density due to mismatch strains; and (ii) increased resistance to dislocation motion imposed by reinforcement at high strain rates.

In a recent study, Bao and Lin [19] used a finite element technique to consider a strain-rate-sensitive matrix containing spherical rigid particles. They found that the local strain-rate distribution in the matrix was quite inhomogeneous and concluded that the increased strain-rate sensitivity of the composite over the matrix was due to the constraining effect of the particles. Their model, therefore, can be extended conceptually to the present case of a short-fiber reinforced composite and provides a convincing basis for qualitative explanation of the present data as follows. As deformation of the composite begins at high strain rates (e.g., $>1000 \mathrm{~s}^{-1}$ ), fibers begin to crack, causing large local strains and correspondingly high strain rates within the matrix. Bao and Lin [19] calculate that the local strain rate can reach 5 times the macroscopic strain rate and under these circumstances the matrix is deforming at a strain rate of about $4000 \mathrm{~s}^{-1}$, i.e., it effectively enters a strain-rate range where it is very strain-rate sensitive (see Fig. 6). Therefore, the strain-rate sensitivity of the composite appears greater than that of the unreinforced matrix because of a significant increase in the contribution of the matrix to the terms of Eq. (4).

Another possible contribution to the increased strainrate sensitivity of the composite is an increase of the compressive strength of the fibers at high strain rates. Lankford [20] found that the compressive strength of polycrystalline bulk $\mathrm{Al}_{2} \mathrm{O}_{3}$ is rate dependent and increases as the strain rate increases. It is well known that bulk and fiber properties of ceramics can be quite different in terms of strength but there are no data relating to the strain-rate sensitivity of mechanical properties for the fiber form of the ceramic materials. Moreover, the associated fracture mechanisms of $\mathrm{Al}_{2} \mathrm{O}_{3}$ between static and dynamic strain rates are not well differentiated and, therefore, analysis of the fiber fracture surfaces could not be expected to give information on the effect of fiber fracture events on the strain-rate sensitivily of the composite studied here.

Although several different mechanisms of increased rate sensitivity of MMCs have been proposed, the exact mechanism is most likely a complex function of the propertics of matrix, fibcrs. interface and the extent of the damage formation. The effects of these parameters will also vary according to the type of MMCs, which may contain a strong or weak interface, short fibers or whiskers, etc.

One of the microstructural effects of strain rate on the composite observed in this study was the reduction of the fiber length distribution at high strain rates compared with the quasi-static rates (Fig. 8). The effect 
of fragmented fiber length is most marked at the lower strains and a relatively small fiber length is attained at large strains in both quasi-statically and dynamically tested samples. This reduction in the fiber length distribution is believed to occur duc to the increase in the strength of the matrix alloy at high strain rates. Assuming all the fiber fracture in the composite procecded by shearing type failure, from Eq. (3) it is expected that the increased matrix flow stress will induce smaller fiber fragment length as long as the fiber fracture strength is independent of strain rate. The experimental observations confirm this rationale.

Composite samples compression tested at different strain rates showed very large plasticity. Some of the specimens were reloaded in the SHPB in an attempt to induce complete fracture of the samples. Such samples attained strains of $50-60 \%$ without complete fracture. However, extensive shear lines were observed on the surface at $45^{\circ}$ to the loading axis and small cracks followed these lines. The large plastic strain attained in compression is in contrast to the relatively small fracture strain of the Saffil reinforced aluminum and magnesium alloys tested in uniaxial tension by other investigators $[4,6]$.

Microstructural damage analysis of the MMC tested at high strain rates and large strains, however, clarifies several different features of the behavior of MMCs under compression as compared with tension in order to explain the large plasticity of the MMC studied here. In tensile testing of Saffil reinforced aluminum [15], fiber fragmentation was studied as a function of the distance from the fracture surface and found to increase in severity close to the fracture surface. In that study the minimum fragment length was also about $20 \mu \mathrm{m}$ but fragmentation only occurred close to the fracture surface, whereas in the present study fragmentation was uniform throughout the sample. Increased fiber fragmentation signals the formation of highly localized deformed regions where fracture usually originates. Microscopic analysis of the fracture sites has further shown that matrix fracture started from fiber clusters [6].

Fracture of the MMC due to localized deformation means that fibers outside the region will not experience their maximum sustainable stress during deformation or until fracture of the test sample. Contrary to tensile testing, matrix cavitation which induces catastrophic fracture is greatly reduced due to the existence of compressive hydrostatic stress. Therefore, in compression, matrix fracture is somewhat delayed, giving time for the long fibers to be reloaded during deformation. This cffect can be easily seen from Fig. 10, where the composite attained a relatively homogeneous and small fiber length distribution around $20 \mu \mathrm{m}$ at relatively large strains (i.e., 33\%) both at quasi-static and dynamic strain rates.

\section{Conclusions}

1. IIigh strain-tate compression behavior of Saffil short-fiber reinforced $\mathrm{Al}-1.17 \mathrm{wt} . \% \mathrm{Cu} \mathrm{MMC}$ has been determined. The composite is significantly more strainrate sensitive than the unreinforced matrix.

2. Quantitative metallography on samples tested quasi-statically or dynamically to different strains showed that higher strain rate induced a relatively smaller fiber fragment length distribution in the composite. This supports observations of increased flow stress of the matrix alloy at high strain rates.

3. The strain-rate sensitivity of the composites can be explained by the increased strain rate in the matrix in the vicinity of the broken or breaking fibers.

4. MMC samples tested at quasi-static strain rates show very large fiber strengthening effects depending on the fiber volume fraction and orientation. Samples tested parallel to the planar random array have higher flow stresses than those tested normal to the planar random array and this anisotropy was confirmed to extend into the high strain-rate range $\left(>\sim 10^{3} \mathrm{~s}^{-1}\right)$.

5. Microscopic damage analysis showed fiber buckling and shear to be principal damage modes at high strain rates. Despite major damage with increasing strain, the increased plasticity in compression, as compared with the fracture mechanisms in tension, is due to the absence of void growth.

\section{Acknowledgements}

The authors gratefully acknowledge financial support for this work from the Department of the Army, US Army Research Office, award \# DAAHO4-95-Z-0005. One of the authors (M.G.) gratefully acknowledges financial support from the Izmir Institute of Technology of Turkey during the course of this work.

\section{References}

[1] J. Harding, M. Taya, Proceedings of ICCM-6/ECCM-2, Elsevier Applied Science, Amsterdam, 1987, p. 2.224.

[2] R. Vaziri, D. Delfosse, G. Pageau, A. Poursartip, International Journal of Impact Engineering 13 (1993) 329.

[3] S. Yadav, D.R. Chichili, K.T. Ramesh, Acta Metallurgica et Materialia 43 (1995) 4453.

[4] T.W. Clyne, M.G. Bader, G.R. Cappleman, P.A. Hubert, Journal of Materials Science 20 (1985) 85.

[5] C.M. Friend, Journal of Materials Science 22 (1987) 3005.

[6] W.J. Clegg, J.F. Horsfall, J.F. Mason, L. Edwards, Acta Metallurgica et Materialia 36 (1988) 2.151.

[7] D.J. Towle, C.M. Friend, Materials Science and Engineering A188 (1994) 153.

[8] A. Kalambur, Dynamic compressive mechanical behavior of a silicon carbide/aluminum metal matrix composite, M.M.S.E. Thesis, University of Delaware, USA, 1996. 
[9] E.D.H. Davies, S.C. Hunter, Journal of the Mechanics and Physics of Solids 11 (1963) 155.

[10] D.J. Towle, C.M. Friend, in: A.R. Bunsell et al. (Eds.), Developments in the Science and Technology of Composite Materials, Proceedings of the 5th European Conference on Composite Materials, Bordeaux, France, European Association for Conposite Materials, 1992, p. 747.

[11] Data Sheet: R.F. Saffil, ICI (Mond. Div.), 1984.

[12] B. Johannesson, S.L. Ogin, Acta Metallurgica et Materialia 43 (1995) 4337.

[13] A.G. Evans, J.W. Hutchinson, R.M. McMeeking, Scripta Metallurgica 25 (1991) 3.

[14] P.S. Follanshee, in: L.E. Murr, K.P. Staudhammer, M.A. Meyers (Eds.), Metallurgical Applications of Shock Wave and
High-Strain Rate Phenomena, Marcel Dekker, New York, 1986, p. 451.

[15] I.W. Hall, in: Proceedings of the 12th Riso International Symposium on Materials Science, Metal Matrix Composites-Processing, Microstructure and Properties. Denmark, 1991, p. 367.

[16] R. Dowling, J. Harding, J.D. Campbell, Journal of the Institute of Metals 98 (1970) 215

[17] G. Regazzoni, U.F. Kocks, P.S. Follansbee, Acta Metallurgica 35 (1987) 2865.

[18] T. Lim, Y.H. Kim, C.S. Lee, K.S. Han, Journal of Composite Materials 26 (1992) 1062.

[19] G. Bao, Z. Lin, Acta Metallurgica et Materialia 44 (1996) 1011.

[20] J. Lankford, Journal of Materials Science 12 (1977) 791. 